\title{
LINGUAGEM, GÊNERO E SEXUALIDADE NA EDUCAÇÃO DE JOVENS E ADULTOS: UMA PROPOSTA DE MULTILETRAMENTOS CRÍTICOS
}

\section{LANGUAGE, GENDER AND SEXUALITY IN YOUTH AND ADULT EDUCATION: TOWARDS CRITICAL MULTILITERACIES}

\author{
André Luiz Souza da Silva ${ }^{1}$ \\ Thayse Silva da Rocha Dias ${ }^{2}$ \\ Fábio Alexandre Silva Bezerra ${ }^{3}$ \\ Universidade Federal da Paraíba (UFPB)
}

\begin{abstract}
RESUMO
Gênero e sexualidade na escola são temas conflituosos na prática pedagógica (MOITA LOPES, 2013). Contrário à crença popular, tratar desses assuntos não se resume a falar abertamente sobre práticas sexuais seguras ou sobre gravidez na adolescência, tampouco se trata de expor os/as estudantes a aparatos que incitem à prática sexual. Com uma compreensão mais ampla sobre como questões de gênero e sexualidades podem impactar o desenvolvimento de alunos/as e sua relação com a aprendizagem, esta pesquisa, de natureza qualitativa e de caráter interpretativista, situada no âmbito da Linguística Aplicada Indisciplinar (KLEIMAN, 2013; MOITA LOPES, 2006), objetiva 1) investigar a recorrência do tema gênero e sexualidades no contexto da EJA (Educação de Jovens e Adultos), e 2) identificar o uso de termos que façam referência às identidades de gênero e às sexualidades. Ademais, propomos práticas de multiletramentos (COPE; KALANTZIS, 2015; ROJO, 2012) nas aulas de língua portuguesa da Educação de Jovens e Adultos (EJA), mediante práticas de leitura, de análise linguística e de escrita guiadas pela Proposta Curricular para a Educação de Jovens e Adultos (BRASIL, 2002) que tematizam gênero e sexualidades na escola com o intuito de possibilitar reflexões sobre diversidade na sociedade contemporânea situadas nas funcionalidades da linguagem (ANTUNES, 2009; BAGNO, 2009). Resultados gerais indicam a necessidade de uma abordagem de identidades de gênero e de sexualidades no contexto escolar que desafie visões essencialistas dos indivíduos e promova uma atitude de respeito à diversidade frente aos desafios que a sociedade contemporânea nos apresenta para além dos muros da escola.
\end{abstract}

PALAVRAS-CHAVE: Ensino de Língua. Multiletramentos. Gênero e Sexualidade. EJA.

\begin{abstract}
Gender and sexuality at school are controversial themes in the pedagogical practice (MOITA LOPES, 2013). Contrary to popular belief, addressing these issues is not be limited to talking openly about safe sexual practices or to discussing teenage pregnancy, nor does it aim at exposing students to apparatuses that incite sexual practice. With a broader understanding about how issues of gender and sexualities may impact students' development and their

\footnotetext{
${ }^{1}$ Mestrando no Programa de Pós-Graduação em Linguística da Universidade Federal da Paraíba, sendo bolsista CAPES. E-mail: andreluiz.bans@gmail.com.

2 Licenciada em Letras-Inglês pela Universidade Federal da Paraíba. Membro do GEPLAM - Grupo de Estudos e Pesquisa em Linguística Sistêmico-Funcional, Análise Crítica do Discurso e Multimodalidade/Multiletramentos (UFPB/CNPq).E-mail: tayase@gmail.com.

3 Doutor em Língua Inglesa e Linguística Aplicada pela Universidade Federal de Santa Catarina. PhD em Linguística pela University of Sydney. Professor do Departamento de Letras Estrangeiras Modernas e do Programa de Pós-Graduação em Linguística da Universidade Federal da Paraíba, onde colidera o GEPLAM Grupo de Estudos e Pesquisa em Linguística Sistêmico-Funcional, Análise Crítica do Discurso e Multimodalidade/Multiletramentos (UFPB/CNPq).E-mail: fabes10@yahoo.com.br.
} 
relationship with learning, this qualitative and interpretative study, situated in the scope of Indisciplinary Applied Linguistics (KLEIMAN, 2013; MOITA LOPES, 2006), aims 1) to investigate the recurrence of the theme gender and sexualities in the YAE context, and 2) to identify the use of terms that refer to gender identities and sexualities. Additionally, we propose practices of multiliteracies (COPE; KALANTZIS, 2015; ROJO, 2012) in Portuguese language classes in Youth and Adult Education (YAE) through practices of reading, linguistic analysis and writing guided by the Curriculum Proposal for Youth and Adult Education (BRASIL, 2002) that address gender and sexualities at school in order to enable reflections on diversity in contemporary society situated in the functionalities of language (ANTUNES, 2009; BAGNO, 2009). Overall results indicate the need for an approach to gender identities and sexualities in the school context that challenges essentialist views of individuals and fosters an attitude of respect towards diversity in light of the challenges posed by contemporary society beyond the school walls.

KEYWORDS: Language teaching. Multiliteracies. Gender and Sexuality. YAE.

\section{INTRODUÇÃO}

Assumirmos uma posição como pesquisadores/as com interesse no processo de ensino-aprendizagem significa também adotarmos uma posição como professores/aspesquisadores/as, os quais não se interessam apenas pelo conhecimento que é produzido academicamente, mas também por explorar seus problemas em sala de aula, com a finalidade de refletir sobre sua práxis. Portanto, o que diferencia o/a professor/a-pesquisador/a "[...] é seu compromisso de refletir sobre a prática, buscando reforçar e desenvolver aspectos positivos e superar deficiências" (BORTONI-RICARDO, 2008, p. 46).

Compreendendo a escola como um lugar de reflexão crítica e de desenvolvimento da cidadania, a partir da problematização das exclusões e dos silenciamentos sociais, a discussão crítica de temas transversais coloca em evidência novas possibilidades, inclusive o potencial de repensarmos nossa própria constituição e "inaugurarmos performances alternativas" a partir da nossa realidade corporificada (MOITA LOPES, 2013, p. 249). Ademais, esse movimento de reflexão crítica é parte de um processo que transpassa todas as etapas da pesquisa e da intervenção pedagógica, sendo, portanto, de vital importância que pesquisadores/as e educadores/as assumam esse lugar de questionamento ao desenvolver um olhar crítico e analítico para as estruturas sociais, os sistemas de significação e as relações de poder, desvelando, assim, processos de normatização e naturalização que fomentam desigualdades, marginalizações e exclusões dos corpos não normativos (BORBA, 2019).

No que diz respeito a Linguística Aplicada (LA), compreendemos a importância da perspectiva queer nos estudos da linguagem (BORBA, 2019), especialmente no tocante à análise dos discursos hegemônicos sobre sexualidades e gêneros e à investigação dos seus efeitos de sentido no campo semântico-pragmático da linguagem. Nessa ótica, buscamos compreender como se estruturam os fenômenos macrossociológicos e como as normatizações, que se concretizam por meio da linguagem-em-uso, têm impacto sobre corpos não normativos e fomentam a percepção social desses corpos como inferiores, desviantes ou patológicos quando julgados em relação à cisheteronorma. Portanto, a perspectiva queer, no âmbito da LA, fornece meios para analisarmos tanto as relações entre língua e identidades, como os processos e estruturas que sustentam concepções normativas, compreendendo, assim, a pesquisa e a intervenção com parte de um posicionamento político no continuum que visa desnortear naturalizações e desessencializar noções normativas sobre as identidades através da problematização de constructos socialmente legitimados e do questionamento de pilares identitários que se concretizam socialmente em íntima relação à linguagem. 
Nesse sentido, temos dois objetivos: a) investigar a recorrência do tema gênero e sexualidades no contexto de ensino da EJA (Educação de Jovens e Adultos), e b) identificar o uso de termos que façam referência às identidades de gênero e às sexualidades, isso à luz das discussões teóricas e da Proposta Curricular da Educação de Jovens e Adultos (PCEJA). A partir dos dados obtidos, propomos práticas de multiletramentos (COPE; KALANTZIS, 2015; ROJO, 2012) que tematizam gênero e sexualidades na escola com o intuito de possibilitar reflexões sobre diversidade na sociedade contemporânea. Para tanto, selecionamos uma letra de canção que norteará as práticas de leitura, de análise linguística, e acionará práticas de escrita. Nesse sentido, compreendemos a importância de construirmos estratégias de intervenção pedagógica com base nesse movimento crítico-analítico, buscando estreitar a relação entre a pesquisa acadêmica e a prática educativa, especialmente no que tange ao contexto da EJA, por se tratar de uma área do ensino com desafios e realidades particulares. Buscamos, assim, construir um projeto de intervenção pedagógica com base na pluralidade e na multiplicidade que transpassa a vida social, tanto no que diz respeito aos modos de linguagem e suas variadas funcionalidades (ANTUNES, 2009; BAGNO, 2009), quanto no que diz respeito às identidades e realidades sociais.

Desta forma, este artigo está organizado da seguinte maneira. Após essas palavras iniciais, apresentamos uma seção de descrição dos procedimentos metodológicos, seguida do aporte teórico, que se faz na proposição de uma visão sobre a emergência de uma postura crítica no campo da LA, bem como traça questões relativas à ação pedagógica por meio dos postulados dos multiletramentos e da multimodalidade, concebendo a validade e a necessidade de um ensino de língua(s) que se proponha a tematizar gêneros e sexualidades, especialmente no contexto da EJA, indicando concepções da PCEJA (2002). Em seguida, apresentamos e problematizamos os resultados dos questionários aplicados e traçamos uma proposta de intervenção para práticas de multiletramentos. Por fim, apresentamos algumas considerações finais a partir da recuperação dos objetivos desta pesquisa.

\section{Procedimentos metodológicos}

No âmbito da LA, esta pesquisa se alinha com a busca de alternativas e caminhos para lidar com uma problemática de relevância social, bem como se interessa pela compreensão da realidade (PAIVA, 2019). Desse modo, a pesquisa é de natureza qualitativa, interessando-nos os significados que os sujeitos atribuem aos contextos socioculturais onde a linguagem tem papel centralizador, pautados em um caráter interpretativista acerca das realidades contemporâneas.

A fim de vislumbrar a familiaridade e a avaliação prévia que os/as estudantes fazem de termos utilizados para identificar identidades de gênero e orientações sexuais, utilizamos um questionário para coleta de dados que ficou disponível em formulário online entre os dias 11 e 21 de julho de 2020, por meio do qual buscamos mensurar o que é percebido como mais ou menos frequente e agressivo. Para oportunizar o acesso ao instrumento de coleta, enviamos links para outros/as professores/as que intermediaram o acesso ao questionário pelos/as estudantes, visto que o cenário imposto pela atual situação de saúde coletiva causada pelo novo coronavírus inviabiliza o contato direto nas escolas. O instrumento foi respondido por 27 discentes da EJA. Para tanto, todos concordaram em participar voluntariamente por meio de termo de consentimento livre e esclarecido.

Para a produção do questionário, selecionamos os termos a partir do dicionário Aurélia: a dicionária da língua afiada, produzido por Vip e Libi (2013) com a finalidade de reunir as gírias e os termos mais comuns para a cultura da comunidade LGBTQIA+, compilando as variantes 
nacionais, itens linguísticos do pajubá ${ }^{4}$ e alguns itens de outros países lusófonos. Os autores asseveram que o material não foi produzido com a pretensão de ser politicamente correto e que variados termos são chulos e pejorativos, o que pode ser ofensivo para algumas pessoas e/ou grupos.

A partir da consulta ao material, selecionamos os termos com função vocativa, ou seja, aqueles que exercem função de chamamento, para compor as alternativas a serem marcadas pelos/as estudantes-informantes. Nesse processo de escolhas, partimos dos itens mais comuns, uma vez que se tornaria inviável a exposição dos/as participantes a todos os verbetes do dicionário. Assim, foi dada prioridade para os termos que remetem a nossa memória escolar discente e docente - e infanto-juvenil. Logo, é necessário explicitarmos que não há padronização quantificável entre os termos que rotulam masculinidades e feminilidades. Em outras palavras, é perceptível que há mais termos que enquadram masculinidades do que feminilidades, dado este que, contudo, não modifica o fato de que existe um uso real desses termos no contexto escolar, no qual o/a professor/a de língua(s) pode intervir e refletir sobre língua, linguagem e seus desdobramentos.

A proposta de intervenção dá-se a partir da letra de canção porque a música mostra-se um mecanismo atrativo no contexto escolar (LO; LI, 1998; MARTINS, 2014; PALACIOS; CHAPETÓN, 2014), possibilitando uma maior aceitação da temática proposta por nós devido à sua complexidade e ao seu caráter, por vezes, polêmico (PEREIRA, 2015). Decidimos utilizar a canção Bixa Preta por ser de autoria e performada por Linn da Quebrada, uma mulher transexual/travesti, que expressa gênero e sexualidade divergentes das padronizações hegemônicas, e também por tratar de temática específica desta pesquisa. Acreditamos que essa representatividade no contexto escolar é premente quando nos deparamos com alarmantes dados sobre transfeminicídios em nosso país.

Como indicam os dados do Grupo Gay da Bahia (OLIVEIRA; MOTT, 2020), o Brasil é um dos países onde mais transexuais e travestis são mortas por ano, somando o alarmante número de 118 em 2019, evidenciando a situação de maior vulnerabilidade dessas pessoas, visto que "o risco de uma pessoa trans ser assassinada é aproximadamente 17 vezes maior do que um gay" (p. 15). Essa realidade, infelizmente, deve, ainda, ser mais claramente situada em um contexto violento nacional no qual é registrada uma morte por homofobia a cada 16 horas segundo relatório da Diretoria de Promoção dos Direitos LGBT do Ministério dos Direitos Humanos, como destaca Sobrinho (2019). Resta evidente, portanto, a urgência do desenvolvimento de pesquisas que abordem tais questões a partir de bases teóricas próprias, sustentadas por caminhos metodológicos adequados à complexidade das investigações que se propõem a articular discussões sobre a inter-relação entre linguagem, gênero e sexualidade (SANTOS FILHO, 2017).

\section{Posicionamentos e perspectivas teóricas}

A LA, em seu caráter trans/indisciplinar, vem rompendo barreiras limítrofes com outras áreas do conhecimento, buscando desestabilizar as fronteiras que envelopam os conhecimentos, viabilizando, assim, um movimento de emancipação epistemológica na renovação do repertório de vozes das produções acadêmicas, bem como na redefinição dos elementos centrais da agenda de pesquisa (KLEIMAN, 2013). A autora ainda aponta para a necessidade de formas de inserção política através da aproximação da LA com "movimentos políticos dos grupos sociais" e na articulação de diálogos com e "para a periferia” (p. 44-45).

\footnotetext{
4 O pajubá é um socioleto que surge a partir do contato da língua portuguesa com elementos linguísticos provenientes de diversos grupos étnico-linguísticos africanos, tais como nagô e iorubá.
} 
Elaborando essa perspectiva política subjacente à pesquisa, a autora destaca a urgência de proposições contra-hegemônicas na "construção social e epistêmica que incorpora os saberes, os modos de ser, os valores de nossos povos" (KLEIMAN, 2013, p. 45). Nesse sentido, é importante desconstruir o viés positivista na produção de conhecimento e reconhecer que, como sujeitos de pesquisa, trazemos nos nossos corpos as marcas da nossa história e, ao mesmo tempo, resgatar as narrativas locais dos atores sociais que agem na e para a periferia. Assim, concebida nossa posição de agentes de pesquisa numa postura de linguistas aplicados, direcionamos discussões que fomentam nossa proposta de ensino. Para tal, valemonos das postulações acerca dos multiletramentos, as quais tiveram início com diálogos e publicação do Grupo de Nova Londres (NEW LONDON GROUP, 2000[1996]), mais recentemente atualizados por Cope e Kalantzis (2015). Essas postulações acerca dos multiletramentos podem ser articuladas com propostas da PCEJA (BRASIL, 2002) com o objetivo de elaborar um projeto de ensino que englobe a diversidade de semioses e de culturas nas práticas de leitura, de análise linguística e de escrita.

As discussões teóricas sobre os multiletramentos (NASCIMENTO; BEZERRA; HEBERLE, 2011; ROJO, 2012) apontam a necessidade de uma prática educativa que considere as pluralidades cultural e semiótica como elementos centrais na escola e na sociedade. Nesse sentido, a relação escola-sociedade aparece na PCEJA associada à tarefa educativa que inclui "o exercício de uma prática escolar comprometida com a interdependência escola/sociedade, tendo como objetivo situar os alunos como participantes da sociedade" (BRASIL, 2002, p. 11). Além disso, segundo o documento, a comunidade escolar tem o papel de oportunizar o aprendizado com foco na leitura, visando à apreensão, à integração e à inserção no mundo, reconhecendo as diferentes capacidades dos/as estudantes e a necessidade de se apropriarem dos conhecimentos coletivamente construídos, como alicerce para a edificação de sua cidadania e suas identidades.

Além disso, a PCEJA (BRASIL, 2002) faz referência a temas transversais que incluem orientação sexual e pluralidade cultural, os quais dialogam com a transformação social e o exercício da cidadania. A partir da interação, das trocas e da inclusão dos temas transversais, espera-se oportunizar o desenvolvimento de uma perspectiva analítica, crítica e reflexiva tanto "sobre os valores e concepções veiculados quanto nas possibilidades de participação e de transformação das questões envolvidas" (p. 23-24).

Dessa forma, trabalhar com temas transversais é uma forma de assegurar aos/às estudantes possíveis caminhos para que se expressem autenticamente sobre questões efetivas, diversidade de pontos de vista e as formas de enunciá-los, bem como a convivência com outros posicionamentos ideológicos em um contexto democrático. Portanto, os temas transversais voltados ao exercício da cidadania também buscam fortalecer a voz de muitos jovens e adultos, para que possam romper os silenciamentos impostos por diversos métodos de exclusão (BRASIL, 2002).

Em relação à multiplicidade de semioses, o documento faz referência à leitura de textos não-verbais, colocando o/a estudante na posição de "decifrador, sempre disposto a perceber as possibilidades intrínsecas que fazem parte da trama, da tecedura, da forma como estão apresentados" (BRASIL, 2002, p. 14-15). Nessa perspectiva, o documento aponta o caráter relacional e constitutivo do texto que é, antes de tudo, uma prática social que se dá na interação com o outro, sendo justamente a concepção da língua como prática social que nos possibilita refletir sobre a sociedade "não só a partir das experiências vividas, mas também daquelas vividas em segunda mão" (BRASIL, 2002, p. 20). Tratando dos textos no âmbito da multimodalidade, Rojo (2012, p. 28) destaca a necessidade de "uma nova ética e de várias estéticas" para tratar das coleções culturais que interagem na escola-sociedade; uma ética para discutir criticamente as éticas e/ou os costumes locais, com vistas a "construir uma ética plural 
e democrática" e, simultaneamente, uma visão crítica das novas estéticas e a construção de "variados critérios críticos de apreciação dos produtos culturais e globais".

Além disso, Rojo (2012, p. 23) destaca como características centrais dos multiletramentos o caráter interativo e colaborativo, o fato de que "fraturam e transgridem as relações de poder estabelecidas" e a constituição dos elementos como "híbridos, fronteiriços, mestiços (de linguagem, mídias e culturas)". Nessa perspectiva, os insustentáveis pares antitéticos devem dar lugar a uma visão desessencializada dos sujeitos, das sociedades e das culturas, construindo uma ótica polissêmica comprometida com "os híbridos, as mestiçagens, as misturas que reinam cada vez mais soberanas" (ROJO, 2012, p. 16).

Nesse sentido, a PCEJA, ao tratar da análise crítica de diferentes discursos, traz pontos em comum com a pedagogia dos multiletramentos quando define que um dos objetivos é que os/as estudantes sejam capazes de interpretar textos, de identificar e de repensar "juízos de valor tanto socioideológicos (preconceituosos ou não) quanto histórico-culturais (inclusive estéticos) associados à linguagem", de forma que possam reafirmar "sua identidade pessoal e social" (BRASIL, 2002, p. 20). Desse modo, a pedagogia dos multiletramentos pode dar auxílio para efetivar os objetivos dispostos no documento, pois trata da análise crítica dos textos (BEZERRA, 2016) tendo a pluralidade como ponto central do projeto de ensino, considerando-se que, conforme exposto na PCEJA (BRASIL, 2002, p. 20-21), "as práticas da língua refletem os vários discursos que circulam e que traduzem o momento da humanidade".

Temas transversais são, dessa maneira, discutidos em relação "à dignidade da pessoa, à igualdade de direitos, à participação e à corresponsabilidade de trabalhar pela efetivação do direito de todos à cidadania" (BRASIL, 2002, p. 65). Ao tratar especificamente do tema Orientação Sexual, os Parâmetros Curriculares Nacionais (PCN) propõem que se "trate da sexualidade como algo fundamental na vida das pessoas", compreendendo que se trata de uma questão "ampla e polêmica, marcada pela história, pela cultura e pela evolução social" (BRASIL, 1998, p. 67). Dessa forma, reafirma um processo de intervenção pedagógica que objetiva compartilhar informações e problematizar questões relacionadas à sexualidade, abarcando posturas, crenças, tabus e valores associados. Portanto, é evidente que o direcionamento para a latência dos temas transversais pode ser associado ao caráter múltiplo e plural das experiências, das vivências culturais e das identidades.

Discutindo Gênero, sexualidade, raça em contextos de letramentos escolares, Moita Lopes (2013) ressalta a mobilidade, transitoriedade, fragmentação e performatividade das identidades e sociabilidades como elementos centrais da contemporaneidade. Essa perspectiva, por sua vez, leva-nos a pensar nos atravessamentos e enlaces das sociabilidades, compreendendo que a pósmodernidade põe em ebulição o potencial de reinvenção, de reescrita das narrativas não prestigiadas e de combate ao apagamento de quem somos através do resgate das histórias e vivências que escapam à normatização hegemônica, mais marcadamente a partir do que podemos denominar Linguística Queer como "uma proposta subversiva de pesquisa na interface língua(gem), gênero e sex(o)ualidade” (SANTOS FILHO, 2020, p. 7).

Nessa ótica, Moita Lopes (2013) argumenta que essa construção hegemônica que produz "legitimidades/ilegitimidades quanto aos gêneros, às sexualidades, às classes sociais, às raças, às línguas etc, vem do hemisfério Norte" (p. 234), compreendido não de maneira geográfica, mas, sim, por meio do reconhecimento do histórico domínio de nações colonizadoras na produção e na disseminação de conhecimentos tidos como legítimos em âmbito global. Em sequência, o autor retoma a discussão de Judith Butler sobre "a fala de ódio (hate speech) em relação a modos de ser humano considerados não legítimos", lançando luz sobre um projeto de letramentos em favor de uma sociedade mais "ética e justa" ao problematizar as práticas sociais excludentes, preconceituosas e fortemente naturalizadas (BUTLER, 1997 apud MOITA LOPES, 2013, p. 235). 
Na obra Undoing Gender, Butler (2004) afirma que "os termos pelos quais a humanidade é reconhecida são mutáveis e socialmente articulados", de forma que se produz "um diferencial entre o humano e o menos-humano" (p. 2$)^{5}$. Como efeito consequente dessas normas, "certos humanos são reconhecíveis como menos humanos, e essa forma de reconhecimento qualificada não leva a uma vida viável", e, ainda, "certas vidas humanas sequer são reconhecidas como humanas, e isso leva ainda a outra condição de vida invivivel" (BUTLER, 2004 , p. 2, grifo nosso). Nessa ótica, as normas codificam intervenções de poder que agem de forma a regular as inteligibilidades de corpos (BENTO, 2017; LOURO, 2019) e de identidades, em vários níveis, nas intersecções entre raça, etnia, classe social, gênero, sexualidade, etc. (AKOTIRENE, 2019; COLLINS; BILGE, 2016).

Nesse sentido, Moita Lopes (2013) aponta para uma inflexão teórica com base nos estudos queer ao visar à "desnormalização de qualquer projeto identitário entendido como natural, dado ou legítimo", implicando, por sua vez, na desconstrução de "categorias binarizantes e cristalizadas" e a compreensão da "natureza discursiva de quem somos com base em concepções pós-estruturalistas e pós-modernistas" (p. 242). As discussões das teorias pósestruturalistas e dos estudos queer trazem para o plano dos (multi)letramentos uma perspectiva "socioconstrutivista do discurso e de quem somos", onde a pesquisa "mostra como o que está ocorrendo em sala de aula é a constituição da vida social", ou seja, enfatiza a intrínseca relação entre o processo de ensino-aprendizagem e a edificação de quem somos como seres sociais (MOITA LOPES, 2013, p. 244) ao compreendermos gêneros e sexualidades como efeitos de sentido que não são preexistentes ao discurso.

\section{Resultados e discussão das respostas aos questionários}

Inicialmente, descrevemos os resultados coletados pelo questionário aplicado via Google Forms, respondido por 27 discentes da EJA. Para tanto, todos/as concordaram em participar voluntariamente por meio de termo de consentimento livre e esclarecido ${ }^{6}$. Nosso primeiro questionamento foi o seguinte: Em algum momento, em sua jornada como aluno/a, você participou de alguma aula ou projeto sobre diversidade sexual e de gênero?

De acordo com a coleta, $51,9 \%$ dos/as estudantes-informantes não tiveram contato com a temática de gêneros e sexualidades no contexto escolar. A partir do exposto, é válido ressaltar que nosso questionamento foi amplo, logo os 48,1\% que responderam ter tido algum contato com o tema poderiam considerar a temática abordada nas aulas de Biologia, Saúde LGBTQIA+ em palestras, discussão sobre respeito às diferenças em aulas de Sociologia e/ou Filosofia, dentre várias possibilidades no contexto educacional. Assim, estabelecemos um direcionamento temático, especialmente voltado à LGBTfobia, uma vez que centralizamos uma discussão voltada aos termos que são utilizados para se referir às múltiplas sexualidades e identidades de gênero, especificamente. A Tabela 1 explicita os termos mais frequentes no contexto escolar como apontado pelos/as alunos/as em resposta à seguinte pergunta: Quais dos itens abaixo você já ouviu/leu pelos corredores da escola, em sala de aula com colegas e professores / as e em conversas com os colegas e amigos/as?

\footnotetext{
5 Todas as traduções feitas neste artigo são de nossa responsabilidade.

${ }^{6}$ Disponível em: https://docs.google.com/forms/d/11M1FoWmWrIm8DiANUVcqAnRSUWKGHJ4fbV

5T9H8drYA/edit?ts=5f36a762. Acesso em: 11 set. 2020.
} 


\begin{tabular}{|c|c|c|}
\hline \multicolumn{3}{|c|}{ Termos já ouvidos/lidos no contexto escolar } \\
\hline TERMOS & QUANTIDADE & PORCENTAGEM \\
\hline Bicha & 20 & $74,1 \%$ \\
\hline Viado & 18 & $66,7 \%$ \\
\hline Gay & 16 & $59,3 \%$ \\
\hline Sapatão & 16 & $59,3 \%$ \\
\hline Biba & 13 & $48,1 \%$ \\
\hline Lésbica & 13 & $48,1 \%$ \\
\hline Travesti & 13 & $48,1 \%$ \\
\hline Baitola & 13 & $46,1 \%$ \\
\hline Traveco & 12 & $44,4 \%$ \\
\hline Boneca & 11 & $40,7 \%$ \\
\hline Homossexual & 11 & $40,7 \%$ \\
\hline Bissexual & 10 & $37 \%$ \\
\hline Bambi & 7 & $25,9 \%$ \\
\hline Transexual & 7 & $25,9 \%$ \\
\hline Assexuado & 6 & $22,2 \%$ \\
\hline Poc-poc & 6 & $22,2 \%$ \\
\hline Goiaba & 5 & $18,5 \%$ \\
\hline Hermafrodita & 5 & $18,5 \%$ \\
\hline Lacraia & 4 & $14,8 \%$ \\
\hline Mona & 4 & $14,8 \%$ \\
\hline Barbie & 3 & $11.1 \%$ \\
\hline Drag Queen & 3 & $11,1 \%$ \\
\hline Caminhoneira & 2 & $7,4 \%$ \\
\hline Fada & 2 & $7,4 \%$ \\
\hline Heterossexual & 2 & $7,4 \%$ \\
\hline Intersexual & 2 & $7,4 \%$ \\
\hline Coronel & 1 & $3,7 \%$ \\
\hline Andrógino & 0 & $0 \%$ \\
\hline Dragonete & 0 & $0 \%$ \\
\hline Fanchona & 0 & $0 \%$ \\
\hline Fedora & 0 & $0 \%$ \\
\hline Queer & 0 & $0 \%$ \\
\hline
\end{tabular}

Tabela 1: Termos já ouvidos/lidos no contexto escolar

Fonte: Nossa autoria

Analisando a Tabela 1, é possível vermos a frequência de uso dos termos ouvidos/lidos na escola, seja nos corredores ou na sala de aula. Os termos baitola, bicha, biba, boneca, gay, homossexual, lésbica, sapatão, traveco, travesti e viado ultrapassam $40 \%$ de frequência, sendo os mais apontados. Partindo da constatação de que há uma relativa paridade na quantidade de termos que, em geral, referem-se a homens e a mulheres listados na Tabela 1, podemos observar que os homens parecem ter suas sexualidades como pauta no contexto escolar mais frequentemente, visto que, dos quatro termos mencionados por mais da metade dos respondentes, três se referem a homens (bicha, viado e gay), enquanto apenas um se refere a mulheres (sapatão), dados que podem sinalizar uma maior tendência para o controle dos corpos e das sexualidades masculinas LGBTQIA+ no contexto escolar.

A mesma tendência se confirma ao considerarmos os setes termos com porcentagem de frequência de uso entre $40 \%$ e $50 \%$, dos quais seis são utilizados para se referir a corporeidades (inicialmente) masculinas (biba, travesti, baitola, traveco, boneca e homossexual) e apenas dois podem se referir a corporeidades (inicialmente) femininas (lésbica e homossexual). 
Além da frequência de uso, também perguntamos quais termos que julgariam (não) serem agressivos a partir das seguintes perguntas no questionário: Assinale os itens que você acredita SEREM agressivos ao se referirem a pessoas LGBT+, e Assinale os termos que você acredita NÃO SEREM agressivos ao se referirem aos LGBT+. Essas perguntas foram incluídas para nos permitir tratar do potencial dos usos linguísticos em sociedade quer seja para o estímulo à emancipação, ao respeito e à liberdade, quer seja para a manutenção do preconceito e da violência, visto que "todas as questões que envolvem o uso da língua não são apenas questões linguísticas; são também questões políticas, históricas, sociais e culturais (ANTUNES, 2009, p. 21, grifos nossos).

Nesse sentido, os termos de maior incidência (viado, sapatão, bicha, biba, baitola, traveco, boneca e travesti) também são os considerados mais agressivos (Tabela 2). Esse resultado nos indica, de maneira bastante contundente, a agressividade das interpelações acerca das sexualidades do homem no contexto escolar, visto que, dos dez termos mais agressivos (acima de $40 \%$ de frequência de uso), nove se referem a esses indivíduos, com a única exceção sendo o termo sapatão.

Atentemos, contudo, para o fato de que o termo sapatão é o quarto mais utilizado $(59,3 \%)$, sendo considerado o segundo mais agressivo (66,7\%). Essa constatação nos aponta o fato de que as mulheres também têm suas sexualidades frequentemente questionadas no contexto escolar, mas o que parece ocorrer é que, diferentemente dos homens, há uma variação menor nos termos comumente utilizados para se referirem a mulheres que não se adequam a expressões de gênero e de sexualidade hegemônicas.

\begin{tabular}{|l|c|c|l|c|c|}
\hline \multicolumn{2}{|c|}{ Não consideram agressivos } & \multicolumn{3}{c|}{ Consideram agressivos } \\
\hline TERMOS & QUANT. & PORC. & TERMOS & QUANT. & PORC. \\
\hline Homossexual & 18 & $66,7 \%$ & Viado & 22 & $81,5 \%$ \\
\hline Bissexual & 16 & $59,3 \%$ & Sapatão & 18 & $66,7 \%$ \\
\hline Heterossexual & 14 & $51,9 \%$ & Bicha & 17 & $63 \%$ \\
\hline Gay & 13 & $48,1 \%$ & Biba & 16 & $59,3 \%$ \\
\hline Transexual & 13 & $48,1 \%$ & Baitola & 16 & $59,3 \%$ \\
\hline Lésbica & 11 & $40,7 \%$ & Traveco & 16 & $59,3 \%$ \\
\hline Assexuado & 10 & $37 \%$ & Boneca & 13 & $48,1 \%$ \\
\hline Intersexual & 7 & $25,9 \%$ & Bambi & 12 & $44,4 \%$ \\
\hline Travesti & 6 & $22,2 \%$ & Travesti & 12 & $44,4 \%$ \\
\hline Hermafrodita & 6 & $22,2 \%$ & Lacraia & 11 & $40,7 \%$ \\
\hline Fada & 5 & $18,5 \%$ & Goiaba & 10 & $37 \%$ \\
\hline DragQ Queen & 5 & $18,5 \%$ & Barbie & 9 & $33,3 \%$ \\
\hline Andrógino & 4 & $14,8 \%$ & Gay & 8 & $29,6 \%$ \\
\hline Coronel & 4 & $14,8 \%$ & Fedora & 7 & $25,9 \%$ \\
\hline Boneca & 3 & $11,1 \%$ & Dragonete & 7 & $25,9 \%$ \\
\hline Bambi & 3 & $11,1 \%$ & Caminhoneira & 7 & $52,9 \%$ \\
\hline Goiaba & 3 & $11,1 \%$ & Poc-poc & 7 & $25,9 \%$ \\
\hline Mona & 2 & $7,4 \%$ & Coronel & 6 & $22,2 \%$ \\
\hline Caminhoneira & 1 & $3,7 \%$ & Mona & 6 & $22,2 \%$ \\
\hline Baitola & 1 & $3,7 \%$ & Fanchona & 4 & $14,8 \%$ \\
\hline Barbie & 1 & $3,7 \%$ & Fada & 4 & $14,8 \%$ \\
\hline Dragonete & 1 & $3,7 \%$ & Hermafrodita & 3 & $11,1 \%$ \\
\hline Viado & 1 & $3,7 \%$ & Assexuado & 3 & $11,1 \%$ \\
\hline Traveco & 1 & $3,7 \%$ & Andrógino & 3 & $11,1 \%$ \\
\hline Queer & 1 & $3,7 \%$ & Transexual & 3 & $11 \%$ \\
\hline Sapatão & 0 & $0 \%$ & Drag Queen & 2 & $7,4 \%$ \\
\hline Fanchona & 0 & $0 \%$ & Bissexual & 2 & $7,4 \%$ \\
\hline
\end{tabular}




\begin{tabular}{|l|l|l|l|c|c|}
\hline Lacraia & 0 & $0 \%$ & Lésbica & 2 & $7,4 \%$ \\
\hline Poc-poc & 0 & $0 \%$ & Queer & 2 & $7,4 \%$ \\
\hline Bicha & 0 & $0 \%$ & Intersexual & 1 & $3,7 \%$ \\
\hline Fedora & 0 & $0 \%$ & Homossexual & 1 & $3,7 \%$ \\
\hline Biba & 0 & $0 \%$ & Heterossexual & 1 & $3,7 \%$ \\
\hline
\end{tabular}

Tabela 2: Termos considerados (não) agressivos

Fonte: Nossa autoria

A partir da Tabela 2, é pertinente indicarmos que o termo dragonete, apesar de zerado na Tabela 1, teve seu sentido presumido como negativo por sete dos vinte e sete informantes, podendo ter sido associado ao termo dragão, que, popularmente, é usado para indicar alguém avaliado como feio/a. Além disso, podemos identificar o termo queer, indicado como de uso agressivo, mesmo não tendo seu uso reconhecido na Tabela 1. Esse dado aponta que a historicização do termo pode ser bastante produtiva no contexto escolar, uma vez que passou por processo de ressignificação, sendo, atualmente, utilizado mais no meio acadêmico no contexto nacional. A partir desses dados, o/a professor/a pode discutir o conceito de cada um dos termos, considerando que viado, sapatão e bicha incidem com maior percentual para termos agressivos, ao passo que homossexual, heterossexual e bissexual marcam percentual elevado como termos adequados. Além dos índices elevados, é preciso considerar os termos com o percentual menor, uma vez que há considerações morfológicas, históricas e discursivas que podem e devem ser refletidas em sala de aula, utilizando dicionários físicos e/ou online, por exemplo.

A partir disso, é possível se levantar alguns questionamentos sobre esses números em sala de aula, tais como: O contexto influenciará o uso? Dependerá de quem diz e/ou de como se diz? Essas e outras questões, que podem servir para o desenvolvimento de diversos tipos de atividades no contexto escolar, dando visibilidade a questões de gênero e de sexualidades, são propostas, a seguir, em uma sequência de atividades que contemplam leitura, análise linguística e escrita. Para tanto, escolhemos o gênero letra de canção como objeto de introdução, a partir da música Bixa Preta de Linn da Quebrada - premiada atriz, cantora e compositora brasileira, reconhecida por seu ativismo na comunidade LGBTQIA+.

\section{Proposta de intervenção}

Esta seção está dividida em momentos que focalizam habilidades para além do caráter linguístico, visto que contemplam a leitura crítica de textos verbais e não verbais, bem como a reflexão sobre a constituição múltipla e plural das identidades. Dito isso, expomos uma proposta de ensino que vise à prática da leitura crítica, da análise linguística, da escrita e da reflexão coletiva, focalizando, como sujeitos sociais, artistas LGBTQIA+, tais como Linn da Quebrada, Pabllo Vittar e Liniker, entre outros/as.

Evidenciamos, portanto, estreita relação entre a proposta aqui apresentada e os multiletramentos, visto que, somadas ao trabalho com recursos semióticos variados, por meio de suportes e mídias plurais, estão questões culturais e identitárias abordadas em sala de aula que permitem que os/as alunos/as desenvolvam competências adequadas para lidar com a diversidade que é marca indelével da sociedade contemporânea, apesar dos incessantes e, por vezes, violentos movimentos conservadores (ALMEIDA; TONIOL, 2018).

$1^{\circ}$ momento - Prática de Leitura (02 aulas)

De acordo com a PCEJA (BRASIL, 2002), a leitura de textos auxilia os/as estudantes "a incorporar uma visão diferente da palavra" para além da decodificação, de forma que sejam 
"motivados a compreender o discurso do outro, interpretar pontos de vista, assimilar e criticar as coisas do mundo" e, ao mesmo tempo, visa "fortalecer a voz" dos/as alunos/as e "romper os silenciamentos impostos pelos perversos processos de exclusão" (p. 12). Nesse sentido, a letra da canção é um instrumento que propicia a interpretação da subjetividade textual e abre espaço para se trabalhar a multimodalidade, uma vez que os elementos sonoros, rítmicos, visuais e textuais não apenas estão presentes, mas dialogam entre si no produto final. Além disso, o eixo temático da canção também propicia o engajamento dos/as estudantes com temas transversais e oportuniza a reflexão coletiva sobre a multiplicidade de culturas e de modos de ser.

Ressaltando a necessidade de se trabalhar com textos de diferentes gêneros, a PCEJA (BRASIL, 2002, p. 14) destaca que "os textos não-verbais (fotos, desenhos, sons, gestos e etc.)" possibilitam aos/às estudantes-leitores/as "perceber as possibilidades intrínsecas que fazem parte da trama, da tecedura, da forma como estão apresentados". Nessa ótica, é possível apresentar a imagem da capa do single (Fig. 1) ${ }^{7}$ para uma leitura coletiva buscando sensibilizar os/as alunos/as para o tema da canção e iniciar a discussão dos sentidos sociais e identitários construídos e representados nos textos. Dito isso, na primeira aula, pode-se discutir a capa do single, questionando quais elementos verbais estão presentes na imagem, e, a partir da resposta (bixa preta), lançar perguntas, como: A quem esse termo se refere, e como se relaciona com a pessoa representada na imagem?

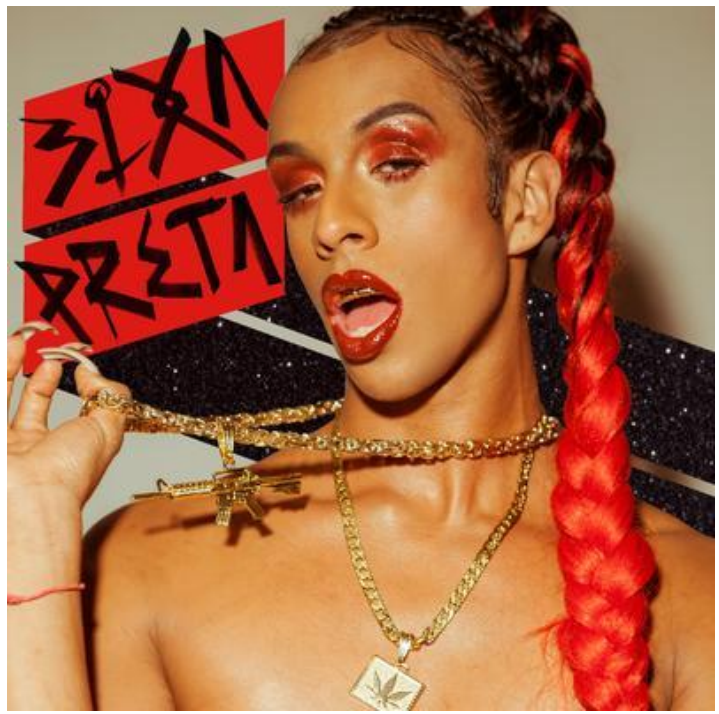

Figura 1: Capa do single Bixa Preta Fonte: Google imagens

Para que os/as alunos/as compreendam a relação entre os recursos composicionais, podemos questionar quais elementos chamam mais atenção e, por sua vez, conectam os termos linguísticos à pessoa que está na imagem. O objetivo é que percebam o uso da cor como um recurso coesivo que traz a saliência a determinados elementos, articulando-os de forma coerente na composição. Dessa forma, o/a professor/a pode auxiliar os/as alunos/as a perceberem que o vermelho, utilizado como forma de destacar o texto verbal, também está presente na pulseira, nas tranças, no batom e na sombra nos olhos da Linn, podendo, a partir disso, conduzir a uma discussão coletiva sobre os sentidos simbólicos associados ao vermelho (cor primária quente) a partir, por exemplo, de seus significados sobre intensidade, calor,

7 A produção de Linn da Quebrada nos concedeu autorização para utilizar esta imagem na publicação deste artigo científico. 
energia ${ }_{s}$ saliência e emoções fortes (CARVALHO, 2013), e sobre perigo, revolução e estímulo (KRESS; VAN LEEUWEN, 2002).

Além disso, pensando a narrativa representacional, o/a professor/a pode questionar o que acontece na imagem, se há alguma ação representada, qual é essa ação e quem a realiza. Nesse caso, a Linn é representada puxando um colar dourado, um gesto que também constrói efeitos de sentido em relação ao título-tema da canção, bem como efeitos conceituais simbólicos pelo uso da cor nos elementos da imagem, visto que o dourado pode indicar glamour, dominação, poder e sedução, além de ser um elemento visual relacionado à cultura do rap como o uso colares, anéis, e grills nos dentes.

Ao tratar da "função estética da linguagem", a PCEJA (BRASIL, 2002, p. 15) aponta a "necessidade de estudar os múltiplos recursos da linguagem: o uso figurado das palavras; o ritmo e a sonoridade; as sequências por oposição ou simetria; repetições expressivas de palavra ou de sons". Nessa ótica, o/a professor/a pode mediar uma primeira escuta da música, trazendo atenção para a presença da onomatopeia bicha pre-, tra, tra, tra, tra, e questionar os possíveis sentidos criados pela sonoridade em associação ao tema da música, visto que o emprego da figura de linguagem remete ao som de armas de fogo, de tiros disparados e, com isso, aponta para a violência e a vulnerabilidade dos corpos marginalizados.

$\mathrm{Na}$ aula seguinte, apresenta-se a letra da canção, interagindo com os/as estudantes a partir de inferências sobre gênero textual e musical para que exponham suas impressões e percebam a linguagem multimodal e poética da música. Em seguida, dividindo a turma em grupos menores, orienta-se uma primeira leitura da letra, instruindo que destaquem termos que causam estranhamento, que chamam atenção, que os provocam, para que pensem em como essas provocações acontecem e por que acontecem.

Conforme aponta a PCEJA (BRASIL, 2002, p. 12), "a língua é um instrumento vivo, dinâmico, facilitador, com a qual é possível participar ativa e essencialmente da construção da mensagem de qualquer texto”. Assim, na primeira estrofe, podemos chamar atenção para os versos quando ela está passando, todos riem da cara dela, propondo que os/as estudantes discutam a razão de o eu-lírico ser ridicularizado para que percebam quem é esse interlocutor que a ridiculariza, discutindo também os significados sociais construídos pelas expressões mas, se liga, macho e mas, daqui en não tô te ouvindo, boy. Ademais, pode-se instruir que os/as alunos/as caracterizem esse macho/boy, posteriormente classificado como macho alfa, discutindo qual ideia de masculinidade se constrói no texto, o que abre espaço para questionarmos os sentidos socioculturais que perpassam a recriação da masculinidade no plano imaginário da canção.

Por fim, o/a professor/a pode mediar uma discussão com toda a turma sobre a relação entre a primeira e a segunda estrofe, particularmente os trechos quando ela tá passando, todos riem da cara dela e quando eu for passar e ninguém mais vai dar risada, voltando-se para essa mudança de atitude e de representação do eu-lírico, tendo em vista que a música, como uma expressão artística da identidade, propicia o engajamento com lutas sociais e com a problematização de processos de exclusão e desumanização.

\section{$2^{\circ}$ momento - Prática de Análise Linguística (02 aulas)}

De acordo com a PCEJA (BRASIL, 2002), faz-se necessário observar a língua em uso, de forma que a variação esteja intrínseca ao processo linguístico, para evidenciar aspectos sociais, por exemplo, os quais possam ser individuais na fala e na escrita. Nesse sentido, é possível evidenciar uma abordagem ao léxico, uma vez que há diferentes empregos de palavras que remetem a um mesmo ser, animado ou inanimado. Nessa direção, estabelece-se a abordagem inicial ao título da canção: Bixa Preta.

De início, é possível discutir com os/as alunos/as sobre o aspecto ortográfico, uma vez que a letra " $\mathrm{x}$ " foge à norma-padrão, sendo o dicionário, nesse contexto, um recurso 
metalinguístico propício para a abordagem desse momento de reflexão linguística. Dessa forma, os/as alunos/as podem constatar que a grafia tida como "correta" está sendo corrompida, visto que "ch" seria a representação gráfica adequada à norma-padrão. E, assim, começa-se a trabalhar com os/as estudantes a ideia de que a autora e intérprete da canção "opõe-se à linguagem corrente (e disso o falante guarda consciência), servindo à descarga afetiva, à injúria [...]” (PRETI, 1984, p. 27).

Portanto, o uso da linguagem não acontece por acaso, questão essa que deve ser pensada e discutida no contexto escolar, evitando limitar-se à norma-padrão, concebendo questões puramente metalinguísticas, com base em regras que eles/as nem (sempre) usam (na fala e/ou na escrita) (GUEDES, 2006). Além disso, a sequência de adjetivos para essa "bixa" é preta, louca, favelada, de forma que se pode questionar o/a estudante sobre o que ele/a compreende por alguém que é preto/a, louco/a e favelado/a, uma vez que há estereótipos que subjazem esses termos. Mas será que a intenção de Linn seria a de se diminuir? Nesse sentido, pode-se, com os/as estudantes, refletir sobre o seguinte:

[...] os rótulos negativos que a sociedade lhe atribui são incorporados pelo eu-lírico para se caracterizar e se diferenciar dos outros, ao passo que essa distinção serve de mote para mostrar que ela "uma bicha, louca, preta, favelada" é uma agente social que se ressignifica e empodera-se ao utilizar a seu favor a adjetivação preconceituosa que lhe deram. (SILVA; VASCONCELOS, 2020, p. 137)

Diante disso, os resultados coletados na pesquisa inicial, por meio do Google Forms, também serão úteis para o processo de reflexão, auxiliando o/a professor/a na recepção e no tratamento de termos que os/as estudantes possam apontar em sala de aula. Assim, o/a professor/a pode deixar o quadro/lousa limpo e pedir aos/às estudantes que mencionem outros termos, a exemplo de bicha, que eles falem/escutem no dia a dia, na escola ou em outros contextos sociais. Além disso, podem pedir aos/às estudantes que, em seus cadernos, façam um quadro, que deve ter uma linha tracejada ao meio, em direção vertical onde deve estar escrito o termo "empoderamento". Em seguida, o/a professor/a deve solicitar aos/às discentes que, no lado direito, na parte superior do quadro, esteja escrito "pejorativo" e, no lado esquerdo, "respeitoso". Em seguida, deve solicitar que os/as estudantes distribuam, dentro desse quadro, os termos por eles/as mencionados, produzindo uma espécie de continuum da relação agressivo/não-agressivo.

A partir disso, o/a professor/a oportuniza a reflexão individual sobre a questão, para, depois, auxiliar na reflexão coletiva. Feito isso, o/a docente pode especular com os/as alunos/as prováveis usos dos termos, pensando em contextos e falantes diversos e também trazer outros termos referentes às identidades de gênero e à sexualidade. Nesse sentido, compreende-se que toda e qualquer manifestação linguística é digna de análise e reflexão, uma vez que, se existem na língua, têm uma funcionalidade (BAGNO, 2009). Essa funcionalidade deve ser refletida em sala de aula por um viés crítico, compreendendo que, através da língua, podemos construir intenções ora pejorativas, ora não, a depender de quem diz, como diz e por que diz.

Nessa ótica, a pluralidade de vivências, experiências, corpos e identidades deverá também ser ponto de reflexão, de forma que os/as alunos/as possam discutir os efeitos sociais de ser bicha, travesti, transexual, percebendo que a inter-relação dessas facetas cria efeitos de sentidos tanto em relação à canção lida, quanto na experiência da intérprete-compositora. Assim, por meio da análise linguística, compreende-se que há um fortalecimento das identidades, como também evidenciam os termos tomba, fecha, causa e lacração.

Dessa forma, é possível trabalhar com a interpretação com base na análise léxicogramatical da letra e na ressignificação dos termos, a partir de uma reflexão coletiva sobre seus efeitos de sentido socioculturais. Dito isso, enfatizamos que a faixa etária da EJA oportuniza 
uma melhor abordagem do tema e da linguagem presente na letra de canção, tendo potencial de contribuir tanto com a formação crítica e social dos/as estudantes da EJA, quanto dos familiares e amigos/as. Afinal, são jovens, adultos/as e idosos/as que, na maioria das vezes, ocupam lugar de liderança em suas famílias e podem contribuir com a formação de outros sujeitos, indo além dos muros da escola, especialmente quando consideramos que, na luta pela desconstrução de preconceitos, devemos contar com todos/as os/as aliados/as possíveis. Como assevera Ribeiro (2019), "falar a partir de lugares é também romper com essa lógica de que somente os subalternos falem de suas localizações, fazendo com que aqueles inseridos na norma hegemônica nem sequer se pensem" (p. 83).

\section{$3^{\circ}$ momento - Prática de Producão Textual (06 aulas)}

Para desenvolver a competência escrita, as habilidades de leitura e escuta de textos são basilares, uma vez que a primeira oportuniza o contato com características internas do gênero e favorece o acesso a informações que irão compor não só a estrutura, mas o conteúdo temático; e a segunda trabalha a percepção e incentiva o uso da oralidade na discussão da temática (BRASIL, 2002). Essas práticas favorecem a produção textual, a qual, segundo a PCEJA, possibilita a ampliação da competência comunicativa dos/as estudantes, considerando tanto a modalidade oral, quanto a escrita. Nesse sentido, evidenciamos o gênero "perfil biográfico", primando pelo trabalho com a modalidade escrita.

Dessa forma, o $3^{\circ}$ momento, composto por 06 aulas, tem como objetivos específicos: a) viabilizar que os/as estudantes construam suas produções escritas em sala de aula como forma de oportunizar a prática de leitura-escrita considerando o/a professor/a como facilitador na elaboração e reelaboração dos textos, observando as especificidades do contexto de ensino da EJA e incluindo aqueles/as estudantes que não dispõem do tempo e/ou dos meios para realização das atividades em horários alternativos; b) transitar entre artistas de diferentes identidades, destacando que a heterogeneidade das categorias identitárias, tanto na comunidade LGBTQIA+ quanto em relação à cis-heterogeneidade, com vistas à reflexão crítica sobre as diferentes realidades e experiências dos/as artistas; c) possibilitar que os/as estudantes tenham espaço para trazer artistas e personalidades com quem tenham familiaridade e afinidade, ou seja, que o trabalho com o gênero textual em sala de aula esteja relacionado à experiência de vida dos/as próprios/as estudantes e que esse seja um elemento central durante todo o projeto.

Para trabalhar o gênero textual na leitura - 2 aulas (45 minutos cada) - o/a professor/a pedirá que os/as alunos/as apresentem um perfil biográfico de um/a artista ou de uma personalidade que admiram. Nessa aula, os/as alunos/as poderão ler o texto ou elaborar oralmente o que encontraram na pesquisa de acordo com seus interesses e as informações que julgarem relevantes. Assim, o/a professor/a terá espaço para confrontar as diferentes realidades de vida dessas personalidades apresentadas pelos/as estudantes, discutindo o gênero musical e a leitura social desse gênero, bem como suas profissões, suas vivências, suas identidades, as possíveis discriminações, as premiações, o posicionamento político dos/as artistas, etc.

Após confrontar essas questões, a terceira aula contemplará os elementos do gênero "perfil biográfico", destacando que o perfil é menor que uma biografia, discutindo o porquê de ser diferente de uma autobiografia, bem como a constituição do texto por paragrafação, o registro linguístico comum e as informações cruciais para o conteúdo temático. Neste momento, o/a professor/a retomará os perfis que os/as estudantes já leram e discutiram em sala, podendo utilizar do recurso de datashow para projetar comparações entre os perfis, destacando os elementos-chave do gênero textual. Na quarta aula, como forma de oportunizar nova leitura, podemos trazer para sala de aula entrevistas escritas ou orais-visuais de artistas 
LGBTQIA+, a saber: Liniker: "Sou dona do meu corpo e das coisas que escolho para mim" (escuta-leitura) ${ }^{8}$, e Pabllo Vittar: "Defendo a pluralidade de oportunidades" (leitura) ${ }^{9}$

Durante a escuta e a leitura, é interessante pedir que os/as alunos/as anotem trechos que possam ser utilizados na produção de perfil da personalidade entrevistada. Realizada a escuta-leitura dos textos, o/a professor/a deve confrontar a realidade dos/as artistas apresentados/as com as demais personalidades apresentadas pelos/as estudantes, indicando as diferenças e as semelhanças entre as histórias de vida desses sujeitos, visto que, a depender de suas sexualidades e identidades de gênero, vão sendo postos à margem e vivenciam diferentes realidades. Como tarefa de casa, o/a professor/a pedirá que preparem uma primeira escrita de um perfil biográfico de um artista LGBTQIA+ de sua escolha, tais como Linn da Quebrada, Pabllo Vittar, Aretuza Lovi, Jaloo, Liniker, Jhonny Hooker, Silva, Jão, Rogéria, Jorge Lafond, Daniela Mercury, dentre outros/as, buscando textualizar fatos da vida do/a artista, pesquisando dados adicionais na internet e trazendo informações que consideram relevantes a partir de textos verbais e/ou multimodais tais como entrevistas no Youtube, shows, imagens, perfis de redes sociais, etc.

Depois de receber os textos, o/a professor/a avaliará o material, qualitativamente, visando não só aspectos gramaticais e ortográficos, mas, especialmente, o temático, seguido da estrutura, e fazendo comentários relevantes sobre a produção dos/as discentes. Feito isso, o/a professor/a preparará a quinta aula para trabalhar as modificações e adequações necessárias, iniciando pelos aspectos temáticos e destacando a coerência das informações sobre a vida da personalidade biografada; depois, com foco na estrutura, discutirá a paragrafação, o uso das margens da folha, o título do texto; e, por fim, se dirigirá às questões ortográficas e gramaticais mais urgentes e comuns aos textos, trabalhando as especificidades que necessitam de resolução no texto individual final.

A partir disso, a sexta e última aula será para a reescrita em sala, a qual deve ser dialogada com o/a professor/a, onde discutirá as dúvidas dos/as alunos/as, trazendo novas sugestões e possibilidades, mas tendo em mente que o/a autor/a do texto é o/a aluno/a. Então, os textos produzidos podem ser digitalizados e utilizados na produção da avaliação bimestral voltada ao processo de análise do texto; pode ser utilizado como objeto de leitura em outras turmas, anos e/ou segmentos; bem como pode ser proposto que professores/as de outras turmas e disciplinas pensem em abordagens que contemplem o uso do material, com vistas a trabalhar a funcionalidade dos textos, oportunizando o ensino centrado no protagonismo dos/as estudantes.

\section{CONSIDERAÇÕES FINAIS}

Diante do que foi exposto, discutido e refletido, estabelecemos que é necessário adotarmos uma postura de linguistas aplicados, compreendendo que é preciso refletirmos sobre a linguagem em tempos, lugares, culturas e sociedades de diversas maneiras, junto às nossas práticas de ensino, adotando perspectivas teórico-metodológicas diversificadas. Nesse sentido, o presente trabalho alcançou seus objetivos de identificar os itens linguísticos que se referem às orientações sexuais e às identidades de gênero no contexto escolar, bem como de construir uma proposta de abordagem do tema gênero e sexualidade, a partir das práticas de leitura, de análise linguística e de produção de textos, indicadas pela PCEJA.

\footnotetext{
8 Disponível em: https://www.youtube.com/watch?v=MzEH7uEZKcQ\&feature=youtu.be. Acesso em: 13 ago. 2020.

9 Disponível em: https://www.atribuna.com.br/variedades/atrevista/pabllo-vittar-defendo-a-pluralidade-deoportunidades-leia-a-entrevista-1.90254. Acesso em: 13 ago. 2020.
} 
É importante ressaltar que a multiplicidade e a heterogeneidade das salas de aula abrem espaço para o imprevisível e podem trazer à tona situações e desafios particulares, de forma que possíveis adequações e adaptações do projeto deverão ser elaboradas em relação às especificidades do contexto de ensino a que se destina. Com o objetivo de antecipar possíveis problemas, destacamos a) o não engajamento ou desinteresse pela temática e/ou pelo/a artista proposto/a pelo/a professor/a; b) preconceitos em relação à temática, à comunidade LGBTQIA+ e/ou ao gênero musical; c) problemas com a direção escolar em relação ao tema transversal que contempla gêneros e sexualidades; d) conflitos ideológicos entre os/as estudantes e/ou discussões acaloradas durante as aulas.

Vale destacar, antes de tratarmos brevemente destes cenários, que estamos cientes da visão histórica tradicional, alinhada mais a uma tradição pedagógica didática (COPE; KALANTZIS, 2015), “de que a educação é neutra, de que existe um terreno emocional 'plano' no qual podemos nos situar" (HOOKS, 2017, p. 262). No entanto, estamos alinhados a uma perspectiva crítica e reflexiva que enxerga os indivíduos inseridos no contexto de ensino e aprendizagem como seres humanos com sentimentos, contradições, potencialidades e limitações. Nesse sentido, acreditamos que qualquer desafio enfrentado por professores/as e alunos/as em sala de aula pode ser visto como oportunidade para criar pontes entre visões de mundos geralmente compreendidas como antagônicas e que, frequentemente, não podem coexistir. Defendemos, portanto, uma prática pedagógica que crie oportunidades para que possamos resolver conflitos de maneira propositiva com vistas ao desenvolvimento de uma sociedade mais equânime e pacífica.

Pensando nos possíveis desafios acima citados, é importante que, mesmo trabalhando com um/a artista LGBTQIA+ previamente escolhido/a pelo/a professor/a, a interação $\mathrm{com} /$ entre os/as estudantes seja estimulada para o engajamento com as atividades e com a temática. Essa interação deve abrir espaço para que tragam suas próprias referências durante todas as etapas do projeto, pois, além de oportunizar as discussões, propicia uma maior possibilidade de participação discente por levar em consideração seus interesses e preferências, tendo em vista que trazemos nossas próprias coleções culturais para a sala de aula e que essas trocas são essenciais para o processo de ensino-aprendizagem. No tocante aos preconceitos, em relação aos aspectos identitários e/ou gêneros musicais, o/a professor/a pode discutir criticamente sobre o trabalho dos/as artistas mencionados/as pelos/as próprios/as estudantes, chamando atenção para a heterogeneidade de performances mesmo se tratando de personalidades/artistas cis e/ou heterossexuais, de forma a desessencializar qualquer noção homogênea sobre categorias identitárias, rompendo, assim, com as lógicas binárias, fortemente opositivas e excludentes.

Dessa forma, a mediação e a postura do/a professor/a frente às questões levantadas pelos/as estudantes devem buscar a construção de um ambiente seguro para discussões, assegurando que estes/as tenham espaço para discordar e dialogar, preferencialmente entre si, mas enfatizando que a criticidade e o respeito devem caminhar lado a lado durante as discussões em todos os momentos do projeto. Em relação a possíveis questionamentos e problemas com a direção e/ou com os/as estudantes sobre a escolha do tema, é importante que o/a professor/a tenha conhecimento de que o seu trabalho está amparado pelos documentos oficiais, de forma que possa se sentir confiante e seguro/a ao trabalhar com a temática, contornando possíveis dificuldades e lançando mão desses documentos como argumento e fundamento sempre que necessário. Por fim, o espaço de reflexão e de discussão coletiva poderá trazer à tona conflitos ideológicos e preconceitos enraizados; portanto, caso surja alguma situação acalorada, é importante que o/a professor/a intervenha de forma sóbria e pontual buscando direcionar a discussão a um rumo produtivo.

No mais, frisamos que as proposições aqui engendradas não finalizam as discussões. Estes escritos são uma contribuição para os/as pesquisadores/as interessados/as no tema, 
bem como para os/as professores/as que buscam ressignificar o ensino de língua, indo além do prescritivismo da norma-padrão, conciliando os contextos socioculturais e linguísticos plurais no processo de formação discente. Por fim, em futuro breve pós-pandemia, desejamos poder continuar desenvolvendo nossas propostas sobre esses temas, e também esperamos que nossos/as colegas de profissão sigam aprimorando suas práticas, em seus contextos específicos de ensino, buscando interagir a partir de suas experiências (e anseios) e contornando possíveis dificuldades e obstáculos vivenciados na prática educativa.

\section{REFERÊNCIAS}

AKOTIRENE, Carla. Interseccionalidade. São Paulo: Sueli Carneiro; Pólen, 2019.

ALMEIDA, Ronaldo de; TONIOL, Rodrigo. Conservadorismos, fascismos e fundamentalismos: análises conjunturais. Campinas: Editora da Unicamp, 2018.

ANTUNES, Irandé. Lingua, texto e ensino: outra escola possível. São Paulo: Parábola Editorial, 2009.

BAGNO, Marcos. Não é errado falar assim: em defesa do português brasileiro. São Paulo: Parábola Editorial, 2009.

BENTO, Berenice. A reinvenção do corpo: sexualidade e gênero na experiência transexual. Salvador: Editora Devires, 2017.

BEZERRA, Fábio. A análise crítica do discurso e os multiletramentos: o papel da linguagem no fazer docente contemporâneo. In: NÓBREGA, C.; ARCOVERDE, R.; BRANCO, S. e FARIAS, W. (org.). Educação linguística e literária: discursos, políticas e práticas. Campina Grande: UFCG, 2016. p. 189-204.

BORBA, Rodrigo. Conhecendo a linguística queer: entrevista com Rodrigo Borba. Revista X, Curitiba, v.14, n. 4, p. 8-19, 2019.

BORTONI-RICARDO, Stella Maris. O professor pesquisador: introdução à pesquisa qualitativa. São Paulo: Parábola Editorial, 2008.

BRASIL. Parâmetros Curriculares Nacionais: temas transversais: orientação sexual. Ministério da Educação. Secretaria de Educação Fundamental. Brasília: MEC/SEF, 1998.

BRASIL. Proposta Curricular para a Educação de Jovens e Adultos: língua portuguesa. Ministério da Educação. Brasília: MEC/SEF, 2002.

BUTLER, Judith. Undoing gender. Nova York: Routledge, 2004.

CARVALHO, Flaviane. A semiótica social das cores e das formas tipográficas: conceitos, categorias e aplicações. Discursos Contemporâneos em Estudos, v. 1, n. 2, p. 47-65, 2013.

COLLINS, Patricia Hill; BILGE, Sirma. Intersectionality. Cambridge, Malden: Polity Press, 2016. 
COPE, Bill; KALANTZIS, Mary. The things you do to know: an introduction to the pedagogy of multiliteracies. In: (org.). A pedagogy of multiliteracies: learning by design. Hampshire, Nova York: Macmillan, 2015. p. 1-36.

GUEDES, Paulo C. A formação do professor de português: que língua vamos ensinar? São Paulo: Parábola Editorial, 2006.

HOOKS, bell. Ensinando a transgredir. a educação como prática da liberdade. Trad. Marcelo Brandão Cipolla. São Paulo: Editora WMF Martins Fontes, 2017.

KLEIMAN, Angela B. Agenda de pesquisa e ação em linguística aplicada: problematizações. In: MOITA LOPES, Luiz Paulo da (org.). Linguística aplicada na modernidade recente: Festschrift para Antonieta Celani. São Paulo: Parábola Editorial, 2013. p. 39-58.

KRESS, Gunther; VAN LEEUWEN, Theo. Colour as a semiotic mode: notes for a grammar of colour. Visual Communication, v. 1, n. 3, p. 343-368, 2002.

LO, Regina; LI, Henry. Songs enhance learner involvement. English Teaching Forum, v. 36, p. 811, 1998.

LOURO, Guacira L. Pedagogias da sexualidade. In: LOURO, Guacira L. (org.). O corpo educado: pedagogias da sexualidade. Belo Horizonte: Autêntica Editora, 2019. p. 7-42.

MARTINS, Erlene. A música na escola. Ensaios Pedagógicos, p. 1-11, jun. 2014.

MOITA LOPES, Luiz Paulo da. Gênero, sexualidade, raça em contextos de letramentos escolares. In: MOITA LOPES, Luiz Paulo da (org.). Linguística aplicada na modernidade recente: Festscbrift para Antonieta Celani. São Paulo: Parábola Editorial, 2013. p. 227-247.

MOITA LOPES, Luiz Paulo da. Linguística aplicada e vida contemporânea: problematização dos construtos que têm orientado a pesquisa. In: MOITA LOPES, Luiz Paulo da (org.). Por uma linguística aplicada indisciplinar. São Paulo: Parábola Editorial, 2006. p. 85-107.

NASCIMENTO, Roseli; BEZERRA, Fábio; HEBERLE, Viviane. Multiletramentos: iniciação à análise de imagens. Linguagem \& Ensino, Pelotas, v. 14, n. 2, p. 529-552, jul./dez. 2011.

NEW LONDON GROUP. A pedagogy of multiliteracies: designing social futures. In: COPE, Bill; KALANTZIS, Mary (org.). Multiliteracies: literacy learning and the design of social futures. Londres: Routledge, 2000[1996]. p. 9-36.

OLIVEIRA, José; MOTT, Luiz (org.). Morte violentas de LGBT+ no Brasil - 2019: relatório do Grupo Gay da Bahia. 1. ed. Salvador: Editora Grupo Gay da Bahia, 2020.

PAIVA, Vera L. M. de O. e. Manual de pesquisa em estudos linguísticos. São Paulo: Parábola Editorial, 2019.

PALACIOS, Nilsen; CHAPETÓN, Claudia. Students' response to the use of songs in the EFL classroom at the public school in Bogotá. Gist Education and Learning Research Journal, n. 9, p. 930, 2014. 
PEREIRA, Paula G. As relações entre língua, cultura, música e o processo de ensinoaprendizagem de língua estrangeira. Estudos Anglo Americanos, n. 43, p. 62-83, 2015.

PRETI, Dino. A gíria e outros temas. São Paulo: Universidade de São Paulo, 1984.

RIBEIRO, Djamila. Lugar de fala. São Paulo: Sueli Carneiro; Pólen, 2019.

ROJO, Roxane. Pedagogia dos multiletramentos: diversidade cultural e de linguagens na escola. In: ROJO, Roxane; MOURA, Eduardo (org.). Multiletramentos na escola. São Paulo: Parábola Editorial, 2012. p. 11-32.

SANTOS FILHO, Ismar. Processos de pesquisa em linguagem, gênero, sexualidade e (questões de) masculinidades. Recife: Pipa Comunicação, 2017.

SANTOS FILHO, Ismar. Linguística queer. Recife: Pipa Comunicação, 2020.

SILVA, André L. S. da; VASCONCELOS, Clara M. de A. Dar ou não dar voz a uma Bixa Preta? Uma leitura da canção de Linn da Quebrada. Temática, Paraíba, v. 16, n. 7, p. 128-142, jul. 2020.

SOBRINHO, Wanderley. Brasil registra uma morte por homofobia a cada 16 horas, aponta relatório. UOL Cotidiano. 2019. Disponível em: https://noticias.uol.com.br/cotidiano/ultimasnoticias/2019/02/20/brasil-matou-8-mil-lgbt-desde-1963-governo-dificulta-divulgacao-dedados.htm?cmpid=copiaecola. Acesso em: 05 abr. 2020.

VIP, Ângelo; LIBI, Fred. Aurélia: a dicionária da língua afiada. 24 ed. São Paulo: Editora do Bispo, 2013. 